\title{
Characteristics of Seasonal Frozen Soil in Hetao Irrigation District under Climate Change
}

\author{
R. X. Duan ${ }^{1,2 *}$, F. Wang ${ }^{1,2}$, and Y. F. Li $^{1}$ \\ ${ }^{1}$ State Key Joint Laboratory of Environmental Simulation and Pollution Control, School of Environment, Beijing Normal University, \\ Beijing 100875, China \\ ${ }^{2}$ China-Canada Center for Energy, Environment and Ecology Research, UR-BNU, School of Environment, Beijing Normal University, \\ Beijing 100875, China
}

Received 10 March 2021; revised 13 June 2021; accepted 12 July 2021; published online 16 August 2021

\begin{abstract}
Seasonal freezing and thawing is a major cause of serious soil salinization in Hetao irrigation area under climate change. In this paper, the Hetao irrigation area has been selected as an example and field monitoring experiments were used to analyze and study the dynamics of soil water, salt, and heat during freezing and thawing periods. The research results show that the unfrozen water presents a "concave" shape change, and as the degree of freezing deepens, the total water content continues to increase; the salt content also shows an increasing trend, with the $0 \sim 100 \mathrm{~cm}$ soil layer salt rate being $43.73 \%$, of which $0 \sim 10 \mathrm{~cm}$ soil layer is $91.56 \%$, followed by the 10 $\sim 20 \mathrm{~cm}$ soil layer, which is $41.78 \%$. The surface aggregation effect is obvious. The temperature data obtained by analysis shows that the freezing process is one-way freezing and the melting process is two-way melting. The above analysis results can provide a scientific basis for scientific planting and soil salinization prevention and control in irrigation areas.
\end{abstract}

Keywords: Hetao irrigation, freezing and thawing periods, climate change

\section{Introduction}

Frozen soil, generally refers to the soil with ice when the soil temperature is $0{ }^{\circ} \mathrm{C}$ or lower, which is generally divided into two categories: seasonally frozen soil, in which the lowest monthly average temperature reaches $0{ }^{\circ} \mathrm{C}$ or below, and the shallow soil layer alternately freezes and melts; the other category is permafrost, the soil keeps frozen for more than two years or longer, and the average annual temperature is lower than $0{ }^{\circ} \mathrm{C}$ (Svoboda and Fuchs, 2017). Permafrost is different from seasonally frozen soil in many aspects, but frozen soil itself cannot be called a material different from ordinary soil, only a state, and form of existence of soil (Chuah et al., 2018). The permafrost area in the world is vast, accounting for more than $20 \%$ of the total land area (Mishra and Singh, 2010). If considering the impact of seasonally frozen soil, the area significantly affected by frozen soil accounts for more than half of the total land area worldwide (Cheng et al., 2020).

In recent years, global climate change has produced more and more extensive effects. Climate change is one of the recent critical issues. IPCC (Inter-governmental Panel on Climate Change) has indicated that the warming of the climate is an indisputable fact (Batibeniz et al., 2020). The global mean temperature $\left(\mathrm{T}_{\text {mean }}\right)$

${ }^{*}$ Corresponding author. Tel.: +86-188-1157-7059.

E-mail address: rxin.duan@ outlook.com (R. X. Duan).

ISSN: 2663-6859 print/2663-6867 online

(C) 2021 ISEIS All rights reserved. doi:10.3808/jeil.202100068. will increase by about $0.3 \sim 4.8^{\circ} \mathrm{C}$ under climate change (Deng et al., 2018). Climate change has also had a profound impact on global glacial permafrost (Svoboda and Fuchs, 2017). In the Siberian permafrost region, its southern boundary has retreated substantially in the past decades, and the permafrost that has been silent for many years shows increasingly active signs, leading to the deepening of the active layer, the lengthening of the ablation period, and even complete ablation (Zhao et al., 2018). Also, permafrost ablation affects groundwater supply and water resources (Dai et al., 2020). Climate warming will increase the depth of seasonal permafrost melting, which may lead to an increase of groundwater, and its cycle will be longer. Glaciers and permafrost retain more than $70 \%$ of the total global freshwater resources (Duan et al., 2020). The melting of glaciers and the activation of permafrost will undoubtedly accelerate the migration of this part of water, resulting in the increase of extreme climate, sea-level rise, and the risk of natural disasters such as floods (Kingston et al., 2015). The increase of human activities in the permafrost area has also brought threats to the ecological environment of the permafrost area. Permafrost is an ideal place for pollutant disposal and storage in the past for a long time because of its low temperature and its very low water conductivity, which makes the movement of water and solute extremely slow (Xin et al., 2006). Under the dual effects of global climate change and human activities, permafrost areas are undergoing profound changes in various aspects (e.g., hydrology, climate, resources, environment and ecology).

Most of the soils in the middle latitudes of the world are 
affected by seasonal freezing and thawing. For seasonally frozen soil, freeze-thaw is one of the causes of soil salinization. Previous studies have focused on the characteristics of soil freezing, water transport mechanism, and salt frost heave (Chen et al., 2016). Liquid water is the main way of water migration in frozen soil (Yang et al., 2010), and it still satisfies Darcy's law, that is, water always migrates from the area with high water potential to the area with low water potential (Chen et al., 2016). Solute in the soil can reduce the freezing temperature of soil water and increase the unfrozen water content, and further weaken the migration of water to the frozen layer (Wang et al., 2018).

In this study, seasonally frozen soil is selected as the research object. In addition to the actual sampling of frozen soil, the mathematical model (SHAW) is also used to deduce and discuss the law of soil moisture, temperature and solute migration, and transformation, which has guiding significance for the rational development and utilization of frozen soil area, repair, and maintenance of frozen soil environment.

\section{Study Area}

Hetao irrigation district is located in Inner Mongolia, China $\left(40^{\circ} 13^{\prime} \sim 42^{\circ} 28^{\prime} \mathrm{N}, 105^{\circ} 12^{\prime} \sim 109^{\circ} 53^{\prime} \mathrm{E}\right)$, where has a continental monsoon climate. The annual average temperature is $6 \sim 8{ }^{\circ} \mathrm{C}$. The irrigation district has little precipitation, the average annual precipitation is $137 \sim 214 \mathrm{~mm}$, and annual evaporation is more than 2,000 mm (Weng, 2007). The irrigation area is 0.57 million ha, with the main planting crops are wheat, maize and sunflower, etc. The district encompasses five counties (Dengkou, Kanghou, Linhe, Wuyuan, and Qianqi). The water from the Yellow River is the main water source for irrigation, averaging about five billion $\mathrm{m}^{3}$ per year. However, due to the decline of the Yellow River annual runoff, water distribution into the Hetao Irrigation District decreases, thus widening the gap between irrigation water supply and demand (Yang et al., 2013). It includes five irrigation domains, namely the Ulan Buhe irrigation domain, the Jiefang sluice irrigation domain, the Yongji irrigation domain, the Yichang irrigation domain, and the Wulat irrigation domain.

The experimental site selected in this study is in the experimental base of the Yongji irrigation domain. The experimental site belongs to the temperate continental monsoon climate, with long sunshine time and large temperature difference between day and night. From June to September, the rainfall is relatively concentrated, with annual precipitation of $200 \sim 250 \mathrm{~mm}$. During the same period of rain and heat, the annual average sunshine duration is about 3200 hours, the annual average temperature is between $3.0 \sim 8.0^{\circ} \mathrm{C}$, and the annual evaporation is between $1900 \sim 2300 \mathrm{~mm}$. Because of less precipitation and large evaporation, the problem of soil salinization is more prominent.

\section{Methodology}

\subsection{The 5TE Sensor}

The 5TE sensor is used in the experiment, which can monitor soil moisture, conductivity, and temperature. Besides, the soil samples are also collected. Sensors are arranged at the depth of $10,20,30,50,80,120$ and $160 \mathrm{~cm}$ from the surface of the soil layer, and the depth of soil sample collection is 10, 20, 40, 60, 80 and $100 \mathrm{~cm}$ from the surface of the soil layer. The main purpose of collecting soil samples is to monitor the total water content and salt content of each layer of soil. The total moisture content was determined by the aluminum box weighing and drying method, and the salt content was determined by conductivity meter when the soil water ratio was 1:5.

\subsection{The SHAW Models}

The SHAW model can be used to study the depth of soil freezing during freezing and thawing in detail and effectively and can simulate the water and solute migration during complex freezing, and include the erosion related to freezing and thawing (Ukkola et al., 2020). Because the process of soil freezing and thawing is relatively complex, the model can better describe the seasonal freezing and thawing process. The model includes the upper boundary of the atmospheric boundary, such as temperature, wind speed, precipitation, humidity, and other meteorological factors, as well as the water, heat, steam, and solute fluxes in the vertical system between the lower boundary of the known soil boundary. The model can calculate the energy, water, and solute fluxes between nodes in the selected time step. During the calculation, the implicit finite difference equation is used for each node.

\subsubsection{Upper and Lower Boundary Energy and Water Vapor Flux}

The upper boundary of the model is the underlying surface, and the input of the whole dynamic process of the model is the solar radiation absorbed by the underlying surface, the net radiation exchange, and the water and heat exchange between the earth and the atmosphere. It mainly includes net radiation, sensible and latent heat fluxes, and soil heat fluxes. The calculation of net radiation adopts the method recommended by the Food and Agriculture Organization of the United Nations (FAO) when calculating reference crop evapotranspiration $\left(\mathrm{ET}_{0}\right)$. For details, please refer to the algorithm steps (FAO-56) provided by the Food and Agriculture Organization of the United Nations.

The sensible and latent heat fluxes are calculated from the temperature and water vapor gradient between the canopy litter, soil surface, and the atmosphere. The calculation formula is as follows:

$H=-\rho_{\alpha} c_{\alpha} \frac{\left(T-T_{\alpha}\right)}{\gamma_{H}}$

where $\rho_{\alpha}, c_{\alpha}$ and $T_{\alpha}$ are the density $\left(\mathrm{kg} / \mathrm{m}^{3}\right)$, specific heat $(\mathrm{J} /$ $\left.\mathrm{kg} \cdot{ }^{\circ} \mathrm{C}\right)$, temperature $\left({ }^{\circ} \mathrm{C}\right)$ of the air at the reference height, $T$ is the temperature of the exchange surface $\left({ }^{\circ} \mathrm{C}\right)$, and $\gamma_{H}$ is the surface heat transfer resistance $(\mathrm{s} / \mathrm{m})$ set for correcting the air stability. The exchange surface can be canopy top, litter layer, snow cover or soil surface. The heat transfer resistance, $\gamma_{H}$ can be calculated by the following formula: 
$\gamma_{H}=\frac{1}{\mu k}\left[\ln \left(\frac{Z_{r e f}-d+Z_{H}}{Z_{H}}\right)+\psi_{H}\right]$

where $\mu$ is the friction velocity $(\mathrm{m} / \mathrm{s})$, which can be calculated by the following formula:

$\mu=\mu k\left[\left(\ln \left(\frac{Z_{r e f}-d+Z_{m}}{Z_{m}}\right)+\psi_{m}\right)\right]^{-1}$

where $k$ is the Von Karman constant, $d$ is the zero-plane displacement, $Z_{H}$ and $Z_{m}$ are the surface roughness of temperature and momentum profiles, $\psi_{H}$ and $\psi_{m}$ are the heat and momentum heat transfer correction coefficients, which can be calculated by the air stability calculation formula:

$S=\frac{k Z_{r e f} g H}{\rho_{\alpha} c_{\alpha} T_{\mu}^{3}}$

Under stable condition ( $\mathrm{s}>0), \psi_{H}=\psi_{m}=4.7 \mathrm{~s}$; in the case of instability $(\mathrm{s}<0), \psi_{m}$ is approximately equal to $0.6 \psi_{H}$. For $\psi_{H}$, we have:

$\psi_{H}=-2 \ln \left(\frac{1+\sqrt{1-16 s}}{2}\right)$

Soil heat flux is calculated based to the residual energy balance, which must meet the heat flux equation of litter and soil profile. The soil temperature and moisture content of the lower boundary can be estimated by the actual soil sample data or by the model. If the water content data is a model estimation, it is assumed that the water vapor flux gradient is only related to gravity in advance. The model can estimate the soil temperature at lower boundary, and the formula is as follows:

$T_{N S}^{j+1}=\left(1-A_{T}\right) T_{N S}^{j}+A_{T} T_{N S-1}^{j}$

where $N S$ and $N S$-1 represent the bottom layer and upper layer of soil, and the superscript represents the start and end values of the time step. The $A_{T}$ value is estimated by the annual damping depth of the underlying soil depth:

$A_{T}=\frac{\Delta t}{24}\left[-0.00082+\frac{0.00983957 d_{d}}{Z_{N S}-Z_{N S-1}}\left(\frac{Z_{N S}}{Z_{N S-1}}\right)^{-0.381266}\right]$

where $\Delta t$ is the selected time step, and the damping depth can be calculated by the following formula:

$d_{d}=\left(2 k_{s} / c_{s} \omega\right)^{1 / 2}$

where $\omega$ is the radial frequency of the annual temperature oscillation, and its value is $1.99 \times 10^{7} / \mathrm{s}$.

\subsubsection{Initial Field and Parameters of the Model}

The input information of the model includes the initial values of snow cover, soil temperature and soil moisture content, the meteorological data day by day or hour by hour, and the information of the test site, including vegetation coverage, snow cover thickness, eluvium, and soil parameters (Tisseuil et al., 2012). The values of soil temperature and moisture content needed by the model are its initial and end values, and the values of temperature and moisture content in the middle period may not be required. Among them, the water content value is the total water content, including liquid water content and solid water content. Daily meteorological data include the maximum and minimum temperature $\left({ }^{\circ} \mathrm{C}\right)$; average dew point temperature $\left({ }^{\circ} \mathrm{C}\right)$; total mileage of daily wind speed $(\mathrm{m} / \mathrm{d})$; precipitation; average solar radiation level observation value $\left(\mathrm{W} / \mathrm{m}^{2}\right)$. Hourly meteorological data include air temperature $\left({ }^{\circ} \mathrm{C}\right)$; wind speed $(\mathrm{mph})$; relative humidity $(\%)$; precipitation (inches); total solar radiation level observation value $\left(\mathrm{W} / \mathrm{m}^{2}\right)$. In this study, hourly meteorological data of Linhe meteorological station (code 53513) were used.

\section{Results and Discussion}

\subsection{Change of Soil Moisture Content}

In the vertical profile of soil, the soil layer is affected by the change of the external temperature, especially the soil layer near the ground is much more affected than the deeper soil layer. Table 1 shows the change of soil volume moisture content in different depths obtained according to the actual soil sampling data during the initial freezing period. A total of three samples were taken on November 3, November 29, and December 21, 2016, respectively. In the initial stage of freezing, the maximum freezing depth of soil is about $30 \mathrm{~cm}$. Table 1 shows that in this stage, $20 \sim 40 \mathrm{~cm}$ soil layer is medium variability, and $10 \mathrm{~cm}$ and below $50 \mathrm{~cm}$ soil layer is weak variability. The soil profile can be divided into three layers: active layer when $C_{V} \geq 0.3$, sub-active layer when $C_{V} \leq 0.1$, and relatively stable layer when $0.1 \leq C_{V} \leq 0.3$. For the initial freezing stage, the $C_{V}$ values of 20 and $40 \mathrm{~cm}$ soil layers are 0.10 and 0.10 , respectively, which are all sub-active layers, indicating that with the gradual freezing of the soil layer, the water in the unfrozen soil layer is constantly moving to the soil layer. Also, the degree of soil freezing in this period is relatively low, and the change in soil water is more intense. The soil layers of $10 \mathrm{~cm}$ and below $40 \mathrm{~cm}$ are relatively stable, and the change of water is relatively gentle.

Table 2 shows the change of soil volume moisture content in different depths during the stable freezing period obtained by sampling. A total of three samples were taken on January 11, 2017, February 7, and March 2, 2017, respectively. In the stage of stable freezing, the maximum freezing depth of soil is about $75 \mathrm{~cm}$. According to the data obtained, in this stage, about 60 $\mathrm{cm}$ soil layer belongs to medium variability, and other soil layers are weak variability. For the stable freezing stage, the $C_{V}$ value of the $60 \mathrm{~cm}$ soil layer is 0.11 , which belongs to the subactive layer. It shows that with the gradual freezing of the soil layer, the water of the unfrozen soil layer continuously migrates 
Table 1. Statistical Analysis of Soil Volume Moisture Content at the Initial Stage of Freezing

\begin{tabular}{llllllll}
\hline $\begin{array}{l}\text { Depth } \\
(\mathrm{cm})\end{array}$ & $\begin{array}{l}\text { Observation } \\
\text { Times }\end{array}$ & $\begin{array}{l}\text { Maximum } \\
\left(\mathrm{m}^{3} / \mathrm{m}^{3}\right)\end{array}$ & $\begin{array}{l}\text { Minimum } \\
\left(\mathrm{m}^{3} / \mathrm{m}^{3}\right)\end{array}$ & $\begin{array}{l}\text { Mean } \\
\left(\mathrm{m}^{3} / \mathrm{m}^{3}\right)\end{array}$ & Variance & $\begin{array}{l}\text { Standard } \\
\text { Deviation }\end{array}$ & $\begin{array}{l}\text { Coefficient of } \\
\text { Variation }\left(C_{V}\right)\end{array}$ \\
\hline 10 & 3 & 0.355 & 0.320 & 0.338 & $2.14 \mathrm{E}-04$ & 0.015 & 0.040 \\
20 & 3 & 0.403 & 0.316 & 0.354 & 0.001 & 0.036 & 0.100 \\
40 & 3 & 0.390 & 0.321 & 0.345 & 0.001 & 0.032 & 0.100 \\
60 & 3 & 0.399 & 0.351 & 0.369 & $4.60 \mathrm{E}-04$ & 0.021 & 0.060 \\
80 & 3 & 0.363 & 0.340 & 0.350 & $8.74 \mathrm{E}-05$ & 0.009 & 0.030 \\
100 & 3 & 0.356 & 0.332 & 0.341 & $1.20 \mathrm{E}-04$ & 0.011 & 0.030 \\
\hline
\end{tabular}

Table 2. Statistical Analysis of Soil Volume Moisture Content in Stable Freezing Period

\begin{tabular}{llllllll}
\hline $\begin{array}{l}\text { Depth } \\
(\mathrm{cm})\end{array}$ & $\begin{array}{l}\text { Observation } \\
\text { Times }\end{array}$ & $\begin{array}{l}\text { Maximum } \\
\left(\mathrm{m}^{3} / \mathrm{m}^{3}\right)\end{array}$ & $\begin{array}{l}\text { Minimum } \\
\left(\mathrm{m}^{3} / \mathrm{m}^{3}\right)\end{array}$ & $\begin{array}{l}\text { Mean } \\
\left(\mathrm{m}^{3} / \mathrm{m}^{3}\right)\end{array}$ & Variance & $\begin{array}{l}\text { Standard } \\
\text { Deviation }\end{array}$ & $\begin{array}{l}\text { Coefficient of } \\
\text { Variation }\left(C_{V}\right)\end{array}$ \\
\hline 10 & 3 & 0.317 & 0.181 & 0.253 & 0.003 & 0.056 & 0.220 \\
20 & 3 & 0.371 & 0.345 & 0.355 & $1.23 \mathrm{E}-04$ & 0.011 & 0.030 \\
40 & 3 & 0.477 & 0.441 & 0.462 & $2.42 \mathrm{E}-04$ & 0.016 & 0.030 \\
60 & 3 & 0.447 & 0.342 & 0.405 & 0.002 & 0.046 & 0.110 \\
80 & 3 & 0.326 & 0.312 & 0.319 & $2.89 \mathrm{E}-05$ & 0.005 & 0.020 \\
100 & 3 & 0.350 & 0.331 & 0.341 & $6.01 \mathrm{E}-05$ & 0.008 & 0.020 \\
\hline
\end{tabular}

Table 3. Statistical Analysis of Soil Volume Moisture Content in the Melting Period

\begin{tabular}{llllllll}
\hline $\begin{array}{l}\text { Depth } \\
(\mathrm{cm})\end{array}$ & $\begin{array}{l}\text { Observation } \\
\text { Times }\end{array}$ & $\begin{array}{l}\text { Maximum } \\
\left(\mathrm{m}^{3} / \mathrm{m}^{3}\right)\end{array}$ & $\begin{array}{l}\text { Minimum } \\
\left(\mathrm{m}^{3} / \mathrm{m}^{3}\right)\end{array}$ & $\begin{array}{l}\text { Mean } \\
\left(\mathrm{m}^{3} / \mathrm{m}^{3}\right)\end{array}$ & Variance & $\begin{array}{l}\text { Standard } \\
\text { Deviation }\end{array}$ & $\begin{array}{l}\text { Coefficient of } \\
\text { Variation }\left(C_{V}\right)\end{array}$ \\
\hline 10 & 2 & 0.368 & 0.280 & 0.324 & 0.002 & 0.044 & 0.140 \\
20 & 2 & 0.606 & 0.370 & 0.488 & 0.014 & 0.118 & 0.240 \\
40 & 2 & 0.507 & 0.375 & 0.441 & 0.004 & 0.066 & 0.150 \\
60 & 2 & 0.480 & 0.386 & 0.433 & 0.002 & 0.047 & 0.110 \\
80 & 2 & 0.500 & 0.389 & 0.445 & 0.003 & 0.055 & 0.120 \\
100 & 2 & 0.454 & 0.327 & 0.391 & 0.004 & 0.063 & 0.160 \\
\hline
\end{tabular}

Table 4. Statistical Analysis of Soil Salt Content at the Initial Stage of Freezing

\begin{tabular}{llllllll}
\hline $\begin{array}{l}\text { Depth } \\
(\mathrm{cm})\end{array}$ & $\begin{array}{l}\text { Observation } \\
\text { Times }\end{array}$ & $\begin{array}{l}\text { Maximum } \\
(\mathrm{g} / \mathrm{kg})\end{array}$ & $\begin{array}{l}\text { Minimum } \\
(\mathrm{g} / \mathrm{kg})\end{array}$ & $\begin{array}{l}\text { Mean } \\
(\mathrm{g} / \mathrm{kg})\end{array}$ & Variance & $\begin{array}{l}\text { Standard } \\
\text { Deviation }\end{array}$ & $\begin{array}{l}\text { Coefficient of } \\
\text { Variation }\left(C_{V}\right)\end{array}$ \\
\hline 10 & 3 & 1.100 & 0.700 & 0.878 & 0.028 & 0.166 & 0.189 \\
20 & 3 & 1.013 & 0.708 & 0.863 & 0.015 & 0.124 & 0.144 \\
40 & 3 & 0.798 & 0.671 & 0.737 & 0.003 & 0.052 & 0.071 \\
60 & 3 & 0.622 & 0.589 & 0.601 & $2.07 \mathrm{E}-04$ & 0.014 & 0.024 \\
80 & 3 & 0.842 & 0.557 & 0.683 & 0.014 & 0.119 & 0.174 \\
100 & 3 & 0.754 & 0.625 & 0.694 & 0.003 & 0.053 & 0.076 \\
\hline
\end{tabular}

to the soil layer. Also, during this period, the soil freezing degree is strong, and the change of soil water under the action of frost heave is relatively strong. Other soil layers belong to the relatively stable layer, and the change of water is relatively gentle. Table 3 shows the change of soil volume moisture content in different depths obtained during the thawing period. A total of two samples were taken on April 2 and May 6, 2017, respecttively. From the data in Table 3 , at this stage, each soil layer belongs to medium variability and each soil layer is sub-active layer. The results showed that the soil moisture was affected by the outside temperature and so on.

Figure 1 shows the water content changes of soil profiles in different depths in three periods based on the soil water content data obtained from soil samples. In the initial freezing period, the soil moisture content of each soil layer is higher, at this time, the soil has not started to freeze. On November 29, the surface soil began to freeze, and affected by the outside temperature, the freezing process was not stable, and the freezing process and melting process alternate. By December 21, the freezing depth had reached $25 \mathrm{~cm}$, but the degree of freezing was low. The water content of 20 and $40 \mathrm{~cm}$ soil is 0.09 and 0.07 $\mathrm{m}^{3} / \mathrm{m}^{3}$ higher than that on November 29 , respectively, because in the process of freezing, the unfrozen water continuously moves to the frozen layer, increasing the soil water content of the frozen layer. In the stable freezing stage, due to the continuous decrease of external temperature, the depth of soil freezing is increasing, which shows that the soil moisture content of the $40 \sim 60 \mathrm{~cm}$ soil layer is increasing. At this stage, the soil moisture content of the $20 \sim 60 \mathrm{~cm}$ soil layer is higher, and most of them are close to the saturated moisture content. The main rea- 
Table 5. Statistical Analysis of Soil Salt Content in the Stable Freezing Period

\begin{tabular}{llllllll}
\hline $\begin{array}{l}\text { Depth } \\
(\mathrm{cm})\end{array}$ & $\begin{array}{l}\text { Observation } \\
\text { Times }\end{array}$ & $\begin{array}{l}\text { Maximum } \\
(\mathrm{g} / \mathrm{kg})\end{array}$ & $\begin{array}{l}\text { Minimum } \\
(\mathrm{g} / \mathrm{kg})\end{array}$ & $\begin{array}{l}\text { Mean } \\
(\mathrm{g} / \mathrm{kg})\end{array}$ & Variance & $\begin{array}{l}\text { Standard } \\
\text { Deviation }\end{array}$ & $\begin{array}{l}\text { Coefficient of } \\
\text { Variation }\left(C_{V}\right)\end{array}$ \\
\hline 10 & 3 & 1.413 & 0.986 & 1.230 & 0.032 & 0.180 & 0.146 \\
20 & 3 & 1.239 & 0.896 & 1.030 & 0.022 & 0.149 & 0.145 \\
40 & 3 & 1.212 & 0.813 & 1.011 & 0.027 & 0.163 & 0.161 \\
60 & 3 & 0.859 & 0.660 & 0.762 & 0.007 & 0.081 & 0.107 \\
80 & 3 & 0.871 & 0.666 & 0.765 & 0.007 & 0.084 & 0.109 \\
100 & 3 & 0.850 & 0.682 & 0.759 & 0.005 & 0.069 & 0.091 \\
\hline
\end{tabular}
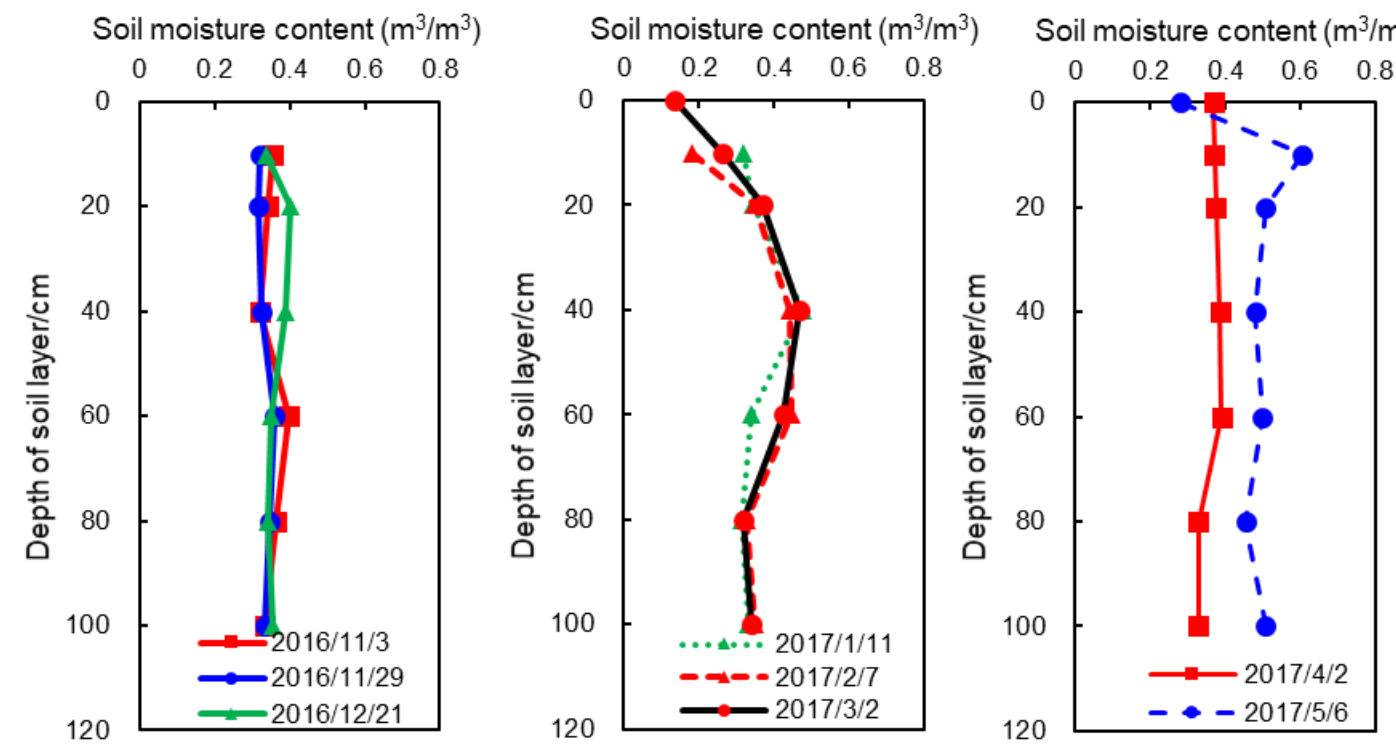

Figure 1. The soil moisture content changes with time (from left to right, the three maps represent the initial freezing period, stable freezing period and thawing period).
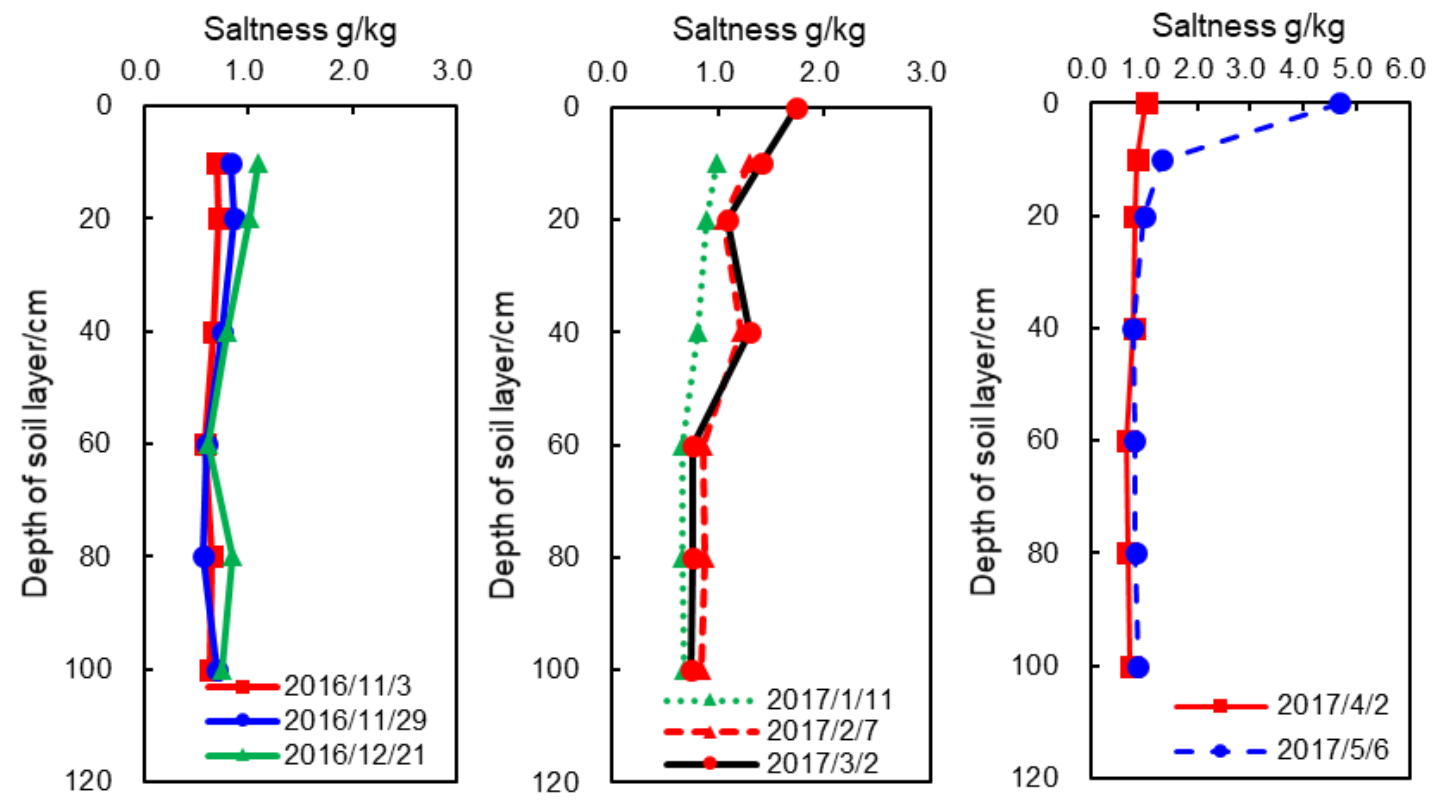

Figure 2. The soil salt content changes with time (from left to right, the three maps represent the initial freezing period, stable freezing period and thawing period). 
son is that during this period, the soil frost heave is strong, the water is constantly moving to the frozen layer, and constantly condensing into ice crystals, which makes the soil moisture content increase. It can be seen from Figure 1 that in the melting stage, except for the decrease of surface soil moisture, the soil water content of other soil layers increased in varying degrees, mainly because the ice crystals in the soil were constantly melting along with the increasing of external temperature at this stage.

\subsection{Change of Soil Salinity}

During the freezing period, the water moves from the unfrozen soil layer to the frozen soil layer, so that the salt also moves with the water to the frozen soil layer. Table 4 shows the changes of soil salt content in different depths at the beginning of freezing. It can be seen from the table that the $C_{V}$ value at 10 $\mathrm{cm}$ soil layer is the largest, which is 0.189 , followed by that at $80 \mathrm{~cm}$ soil layer, which is 0.174 . It shows that in this period, because of the instability of soil freezing, the soil moisture changes greatly, which leads to the instability of soil salt content. The soil layer of $10 \sim 20 \mathrm{~cm}$ shows strong variability, which is medium variability. The other soil layers are weak variability except for $80 \mathrm{~cm}$. The reason may be related to the decrease in groundwater level and the soil texture at $80 \mathrm{~cm}$. For the initial stage of freezing, the $C_{V}$ values of the $10 \sim 20 \mathrm{~cm}$ soil layer are 0.189 and 0.144 , respectively, which are all sub-active layers, indicating that with the gradual freezing of the soil, the water in the unfrozen soil layer is constantly migrating to the soil layer. Due to the low degree of soil freezing, the change of soil moisture is more intense, which leads to the change of soil salt content more active.

Table 5 shows the change of soil salt content during the stable freezing period. The results showed that the $C_{V}$ value was the highest at $40 \mathrm{~cm}$, which was 0.161 , followed by that at 10 $\mathrm{cm}$, which was 0.146 . The $C_{V}$ value of $10 \sim 40 \mathrm{~cm}$ soil layer was larger, and the $10 \sim 40 \mathrm{~cm}$ soil layer showed strong variability, which was a medium variation. The $C_{V}$ values of the 10 $\sim 40 \mathrm{~cm}$ soil layer is $0.146,0.145$, and 0.161 , which belong to the sub-active layer. It shows that with the gradual freezing of the soil layer, the water in the unfrozen soil layer is continuously transported to the frozen soil layer under the action of frost heaving, which makes the salt continuously accumulated. Table 6 shows the statistical results of soil salt content in the dissolution period. Among them, the surface soil salt content $C_{V}$ value is the largest, which is 0.64 , belonging to medium variability, belonging to the active layer, followed by $10 \mathrm{~cm}$ soil, $C_{V}$ value is 0.22 . The results show that in the dissolution stage, with the continuous diffusion of water, the salt continuously accumulates upward, leading to the accumulation of salt in the topsoil.

Using the soil sample data of the whole freeze-thaw period, the salt accumulation of the $0 \sim 100 \mathrm{~cm}$ soil layer is analyzed, as shown in Table 7 . It can be seen from the table that the overall salt accumulation rate of the $0 \sim 100 \mathrm{~cm}$ soil layer is $43.73 \%$, of which the salt accumulation rate of $0 \sim 10 \mathrm{~cm}$ soil layer is $91.56 \%$, followed by the $10 \sim 20 \mathrm{~cm}$ soil layer, $41.78 \%$. The ef- fect of salt accumulation on the surface layer of soil is obvious. Figure 2 shows the salt content changes of soil profiles in different depths in three periods based on the soil water content data obtained from soil samples. In the initial freezing period, due to autumn irrigation, the salt content of the soil in this period is generally low, and the average value of each soil layer is about the same, which is $0.7 \mathrm{~g} / \mathrm{kg}$; by November 29 , when the unstable freezing began, the salt content of $10 \sim 20 \mathrm{~cm}$ soil increased. Among them, the soil salt content at $10 \mathrm{~cm}$ increased by $0.13 \mathrm{~g} / \mathrm{kg}$, at $20 \mathrm{~cm}$ increased by $0.16 \mathrm{~g} / \mathrm{kg}$, and the change degree of other soil layers was small; by December 21, the soil was further frozen, and the soil salt content at $10 \mathrm{~cm}$ increased by $0.266 \mathrm{~g} / \mathrm{kg}$ compared with November 29 , at $20 \mathrm{~cm}$ increased by $0.146 \mathrm{~g} / \mathrm{kg}$.

During the stable freezing period, in three different periods, the salt content of the soil gathered to the surface soil layer: on January 11, the salt content of the soil at $10 \mathrm{~cm}$ was $0.986 \mathrm{~g} / \mathrm{kg}$; on February 7, the value at $10 \mathrm{~cm}$ was $1.292 \mathrm{~g} / \mathrm{kg}$, increased by $0.306 \mathrm{~g} / \mathrm{kg}$ compared with January 11 . By March 2 , the value at $10 \mathrm{~cm}$ was $1.413 \mathrm{~g} / \mathrm{kg}$, increased by $0.427 \mathrm{~g} / \mathrm{kg}$ compared with January 11 , increased by $0.121 \mathrm{~g} / \mathrm{kg}$ compared with February 7 , and the salt content of the surface soil reached $1.744 \mathrm{~g} / \mathrm{kg}$ on March 2, which had the obvious effect of surface accumulation. During the melting period, the soil salt accumulated to the surface soil layer: on May 6, the salt content of the surface soil layer was $4.69 \mathrm{~g} / \mathrm{kg}$, and the $10 \mathrm{~cm}$ was $1.34 \mathrm{~g} / \mathrm{kg}$, which was 0.64 $\mathrm{g} / \mathrm{kg}$ higher than that on November 3 . The surface accumulation effect was obvious.

\subsection{Change of Soil Temperature}

\subsubsection{Seasonal Distribution of Soil Temperature}

Hetao irrigation area is a seasonal freezing and thawing area. The annual average temperature is relatively low, but it is above $0{ }^{\circ} \mathrm{C}$. In late November, the external temperature began to decrease gradually to $0{ }^{\circ} \mathrm{C}$, and the freezing and thawing about six months began. During the freezing process, the soil temperature of different soil layers gradually decreases with the gradual decrease of the external temperature, that is, the temperature of the soil layer decreases from top to bottom according to the depth of the soil layer, so the soil freezing process is a oneway freezing process from top to bottom. For the melting process, due to the increase of the external temperature and the deep soil temperature, the melting process starts from the ground surface downward and the maximum frozen layer depth upward simultaneously, that is, two-way melting.

In the initial stage of freezing, the soil temperature of different soil layers decreased in turn with the decrease of external temperature. Three typical periods (November 3, November 29 and December 21,2016) were selected to analyze the vertical distribution of soil temperature. During the stable freezing period, the soil is further frozen and the degree of freezing is more compact. Four typical time points (January 11, February 10, March 3 and March 10, 2017) are selected to describe the seasonal changes of soil temperature in different depths during this period. During the melting stage, the soil gradually melted, and the seasonal changes of soil temperature in different soil layers 
Table 6. Statistical Analysis of Soil Salt Content in the Melting Period

\begin{tabular}{llllllll}
\hline $\begin{array}{l}\text { Depth } \\
(\mathrm{cm})\end{array}$ & $\begin{array}{l}\text { Observation } \\
\text { Times }\end{array}$ & $\begin{array}{l}\text { Maximum } \\
(\mathrm{g} / \mathrm{kg})\end{array}$ & $\begin{array}{l}\text { Minimum } \\
(\mathrm{g} / \mathrm{kg})\end{array}$ & $\begin{array}{l}\text { Mean } \\
(\mathrm{g} / \mathrm{kg})\end{array}$ & Variance & $\begin{array}{l}\text { Standard } \\
\text { Deviation }\end{array}$ & $\begin{array}{l}\text { Coefficient of } \\
\text { Variation }\left(C_{V}\right)\end{array}$ \\
\hline 10 & 2 & 4.688 & 1.032 & 2.860 & 3.341 & 1.828 & 0.640 \\
20 & 2 & 1.342 & 0.861 & 1.101 & 0.058 & 0.241 & 0.220 \\
40 & 2 & 1.004 & 0.817 & 0.911 & 0.009 & 0.094 & 0.100 \\
60 & 2 & 0.809 & 0.782 & 0.796 & $1.81 \mathrm{E}-04$ & 0.013 & 0.020 \\
80 & 2 & 0.817 & 0.669 & 0.743 & 0.005 & 0.074 & 0.100 \\
100 & 2 & 0.837 & 0.687 & 0.762 & 0.006 & 0.075 & 0.100 \\
\hline
\end{tabular}
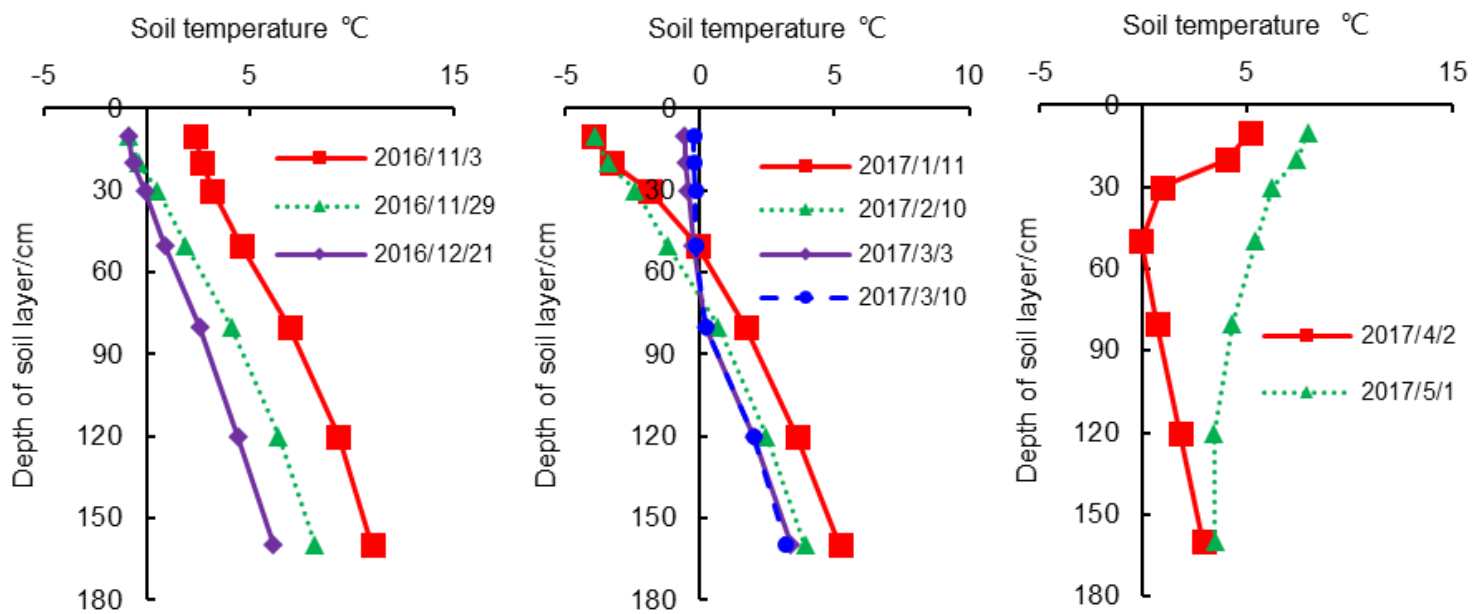

Figure 3. Seasonal variation of soil temperature (from left to right, the three maps represent the initial freezing period, stable freezing period, and thawing period).

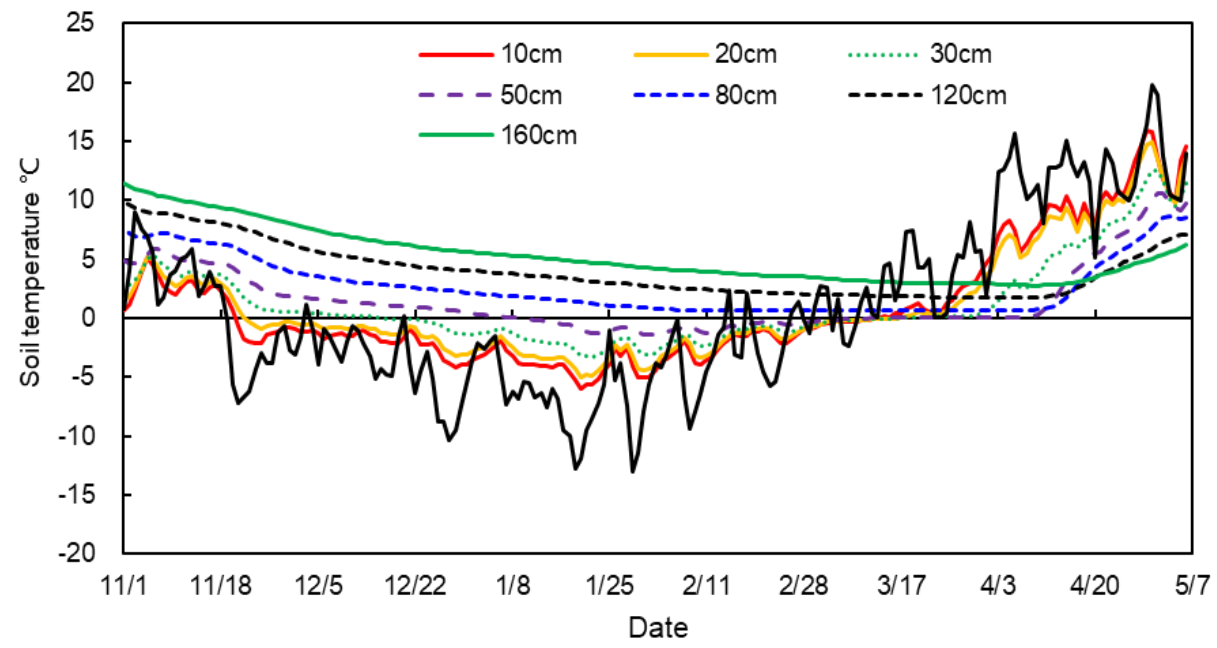

Figure 4. Time series change of soil temperature (the black solid line represents the mean temperature of the atmosphere).

during the period were analyzed by selecting two typical time points $(2017 / 4 / 2$ and 2017/4/20).

As shown in Figure 3, the results show that the soil temperature of each soil layer has been reduced in the early stage of freezing, indicating that the soil freezing process has been continuing. In the stable freezing period, the temperature of the near-earth layer is lower than that of the deep soil layer. Because of the gradual increase of the external temperature, the soil temperature of the near-earth layer also rises gradually, and the rising range is larger than that of the deep soil, which indicates that the influence of the external temperature on the nearearth layer is larger than that of the deep soil layer. In the thawing period, due to the gradual increase of the external temperature, the soil temperature of $0 \sim 50 \mathrm{~cm}$ in the near soil layer also gradually rises, and the rising range is larger than that of the soil below $50 \mathrm{~cm}$ in the deep layer, which also shows that the 
near soil layer is more affected by the external temperature than the deep layer. Figure 4 shows the change of soil temperature time series. The time sequence when the soil temperature of 10 $\sim 50 \mathrm{~cm}$ soil layer reaches zero degrees is $2016 / 11 / 21,2016 / 11 /$ $23,2016 / 12 / 17,2017 / 1 / 11$. The soil layer of $80 \sim 160 \mathrm{~cm}$ does not reach zero degrees or below, indicating that the soil is not frozen. During the thawing period, the time when the soil layer of $10 \sim 70 \mathrm{~cm}$ reaches zero degrees and below is $2017 / 3 / 13,2017$ /3/16, 2017/3/16, 2017/4/3, 2017/3/20.

Table 7. Changes of Soil Salt Storage in Each Soil Layer during Freeze-Thaw Period

\begin{tabular}{lllll}
\hline $\begin{array}{l}\text { Depth } \\
(\mathrm{cm})\end{array}$ & $\begin{array}{l}S S_{E} \\
(\mathrm{~g} / \mathrm{kg})\end{array}$ & $\begin{array}{l}S S_{B} \\
(\mathrm{~g} / \mathrm{kg})\end{array}$ & $\Delta S(\mathrm{~g} / \mathrm{kg})$ & $\begin{array}{l}\text { Salt } \\
\text { Accumulation } \\
\text { Rate }(\%)\end{array}$ \\
\hline $0 \sim 10$ & 1.342 & 0.700 & 0.641 & 91.560 \\
$10 \sim 20$ & 1.004 & 0.708 & 0.296 & 41.780 \\
$20 \sim 40$ & 0.782 & 0.671 & 0.112 & 16.620 \\
$40 \sim 60$ & 0.817 & 0.589 & 0.228 & 38.700 \\
$60 \sim 80$ & 0.837 & 0.650 & 0.187 & 28.830 \\
$80 \sim 100$ & 0.886 & 0.625 & 0.261 & 41.710 \\
Total & 5.669 & 3.944 & 1.725 & 43.730 \\
\hline
\end{tabular}

\subsubsection{Freezing and Melting Characteristics of the Soil Profile}

From the freezing characteristics of the soil profile, it can be observed that the frozen layer of soil in the freezing period is constantly moving down, showing a trend of one-way freezing. At the same time, in the melting period, there is a trend of two-way melting. Figure 5 shows the freezing and thawing characteristics of the soil profile.

In the initial freezing period (late November), the depth of soil freezing is about $20 \mathrm{~cm}$, and the external temperature is above $0{ }^{\circ} \mathrm{C}$ during the day, which leads to the instability of soil freezing. Due to the absorption of solar radiation heat, the temperature of frozen soil increases, leading to the melting of a small part of frozen soil. At night, when the external temperature drops, the soil heat loss is greater than the absorbed heat, resulting in the soil temperature drop and freezing again. Soil freezing at this stage is unstable. Among them, the $0 \sim 20 \mathrm{~cm}$ soil layer is unstable in freezing, the $20 \sim 30 \mathrm{~cm}$ soil layer temperature is close to $0{ }^{\circ} \mathrm{C}$, which is a quasi-frozen layer, and the soil layer below $30 \mathrm{~cm}$ is known frozen. With the further decrease of external temperature, the depth of soil freezing will be further deepened. By the end of December, the external temperature and soil temperature further decreased, the unstable frozen layer became a stable frozen layer, and the quasi-frozen layer depth further increased. Among them, $0 \sim 20 \mathrm{~cm}$ is the frozen layer, and the degree of freezing is denser than that at the initial stage of freezing. The soil temperature at $30 \mathrm{~cm}$ is close to $0{ }^{\circ} \mathrm{C}$, which is a quasi-frozen layer, and the non-frozen layer is below $50 \mathrm{~cm}$.

During the stable freezing period, in January, the depth of soil freezing is about $50 \mathrm{~cm}$. The further decrease of the external temperature makes the soil temperature of each soil layer decrease in varying degrees, and the soil is frozen and compacted. By the middle of February, the outside temperature and the soil temperature were further reduced. Currently, the soil freezing depth was between 70 and $80 \mathrm{~cm}$, which was consistent with the actual situation that the measured freezing depth was $75 \mathrm{~cm}$. At the beginning of April, the temperature of the nearsurface soil layer and the deep soil layer first reached above zero, and they began to melt from top to bottom and from bottom to top respectively, while the $50 \mathrm{~cm}$ soil layer was still in the freezing stage, indicating that the melting process was twoway melting.

\subsection{The Simulation of Soil Moisture and Temperature with the SHAW Model}

Soil freezing and thawing is a relatively complex process, especially the movement of soil water and solute during the freezing period. SHAW model can better describe the seasonal soil freezing and thawing process. The fitting degree of the simulated value and the measured value is tested by the Root Mean Square Error (RMSE), the determination coefficient $\left(R^{2}\right)$, and the Mean Relative Error (MRE). Table 8 shows the MRE, RMSE and $R^{2}$ values of measured and simulated soil moisture content of $0 \sim 100 \mathrm{~cm}$ soil layer in the freezing period calculated by the SHAW model. The mean values of the three indexes are $7.84 \%$, $6.82 \%$ and 0.70 , respectively, which better reflect the law of soil water movement in the freezing period.

Figure 6 shows the comparison between the simulated and measured values of soil water content in different depths during the freezing period. It can be seen from the figure that the simulated value is close to the measured value and can reflect the movement of soil water at this stage. The RMSE, $R^{2}$ and MRE values of the measured and simulated soil temperature during the freezing period are calculated. From Table 9, the mean values of MRE, RMSE and $R^{2}$ are $25.80 \%, 66.89 \%$, and 0.98 , respectively, which better reflects the change law of the temperature during the freezing period, indicating that the simulated value of the model can better reflect the change law of the measured value. The following Figure 7 shows the comparison of simulated and measured soil temperature values at different depths during the freezing period. It can be seen from the figure that the simulated value of temperature is close to the measured value, which can reflect the change in soil temperature at this stage. From the results of the two comparisons, we can see that the SHAW model can better simulate the change process of soil temperature in different soil layers during the freezing period, and it has a certain credibility.

\section{Conclusions}

In this study, the changes in soil moisture, salinity, and temperature during the freezing and thawing periods of seasonally frozen soil were analyzed. At the same time, the model of SHAW was used to simulate the soil moisture and temperature during the freezing period.

Freezing occurs at night, and the high temperature in the day makes the frozen soil layer partially melt in the early stage of freezing. With the increase of the degree of freezing, the unfrozen soil water continuously moved to the frozen layer, increasing the soil water content in the frozen layer. During the stable freezing period, the soil moisture content of the $20 \sim 60 \mathrm{~cm}$ soil 
Table 8. RMSE, $R^{2}$ and MRE of Simulated and Measured Soil Moisture Content during the Freezing Period

\begin{tabular}{lllllll}
\hline & $2016 / 11 / 29$ & $2016 / 12 / 21$ & $2017 / 01 / 11$ & $2017 / 02 / 07$ & $2017 / 03 / 02$ & AVERAGE \\
\hline MRE\% & 12.550 & 16.290 & 5.770 & 1.130 & 3.450 & 7.840 \\
RMSE\% & 6.700 & 9.310 & 6.970 & 4.110 & 6.980 & 6.820 \\
$R^{2}$ & 0.280 & 0.520 & 0.820 & 0.950 & 0.940 & 0.700 \\
\hline
\end{tabular}

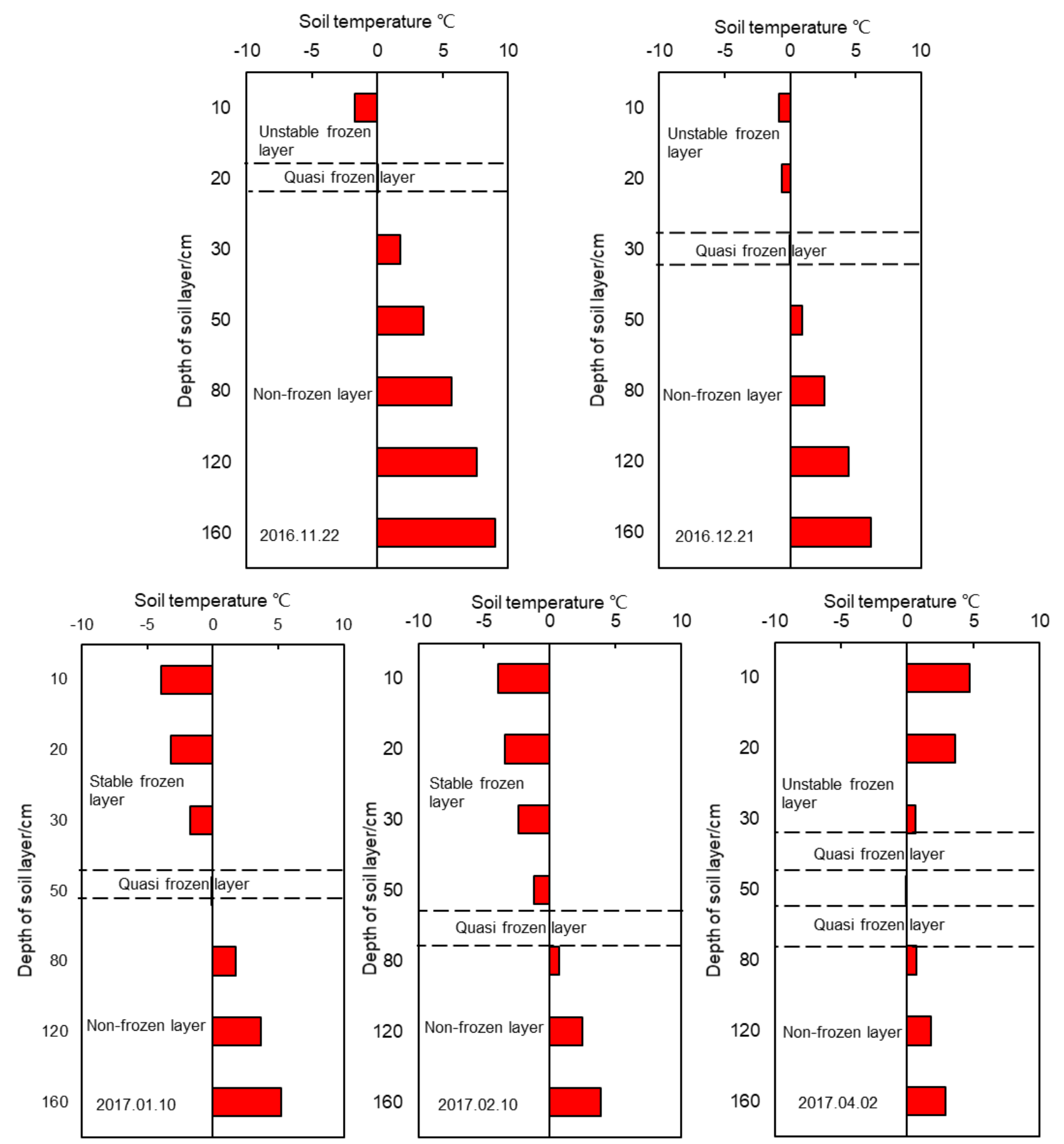

Figure 5. Freezing and melting characteristics of the soil profile. 
layer is close to the saturated moisture content. The main reason is that the soil frost heaving in this period led to the migration of water to the frozen depth and the formation of ice crystals, leading to a higher soil moisture content. Salt in the soil moves with water. At the beginning of freezing, the salt content of $10 \sim 20 \mathrm{~cm}$ soil increased. Among them, the salt content of the soil layer at $10 \mathrm{~cm}$ increased by $0.13 \mathrm{~g} / \mathrm{kg}$, and that at $20 \mathrm{~cm}$ increased by $0.16 \mathrm{~g} / \mathrm{kg}$, and other soil layers had little change. With the decrease of the outside temperature, the soil is further frozen, and the salt content of $10 \sim 20 \mathrm{~cm}$ soil is further increased compared with the initial stage of freezing. At the thawing stage, the salt content of the surface soil is $4.69 \mathrm{~g} / \mathrm{kg}$, and that at $10 \mathrm{~cm}$ is $1.34 \mathrm{~g} / \mathrm{kg}$, which is $0.64 \mathrm{~g} / \mathrm{kg}$ higher than that at the initial stage of freezing.

The soil temperature is affected by the external temperature. In the process of freezing, the soil temperature gradually decreases from $160 \mathrm{~cm}$ soil layer upward. The soil temperature of $10 \sim 50 \mathrm{~cm}$ soil layer has reached zero and below successively

Table 9. RMSE, $R^{2}$ and MRE of Simulated and Measured Soil Temperature during the Freezing Period

\begin{tabular}{lllllll}
\hline & $2016 / 11 / 29$ & $2016 / 12 / 21$ & $2017 / 01 / 11$ & $2017 / 02 / 07$ & $2017 / 03 / 02$ & AVERAGE \\
\hline MRE\% & 21.020 & 188.520 & -9.940 & -46.360 & -24.210 & 25.800 \\
RMSE\% & 50.830 & 122.340 & 57.740 & 80.830 & 22.730 & 66.890 \\
$R^{2}$ & 0.980 & 0.990 & 0.990 & 0.980 & 0.970 & 0.980 \\
\hline
\end{tabular}
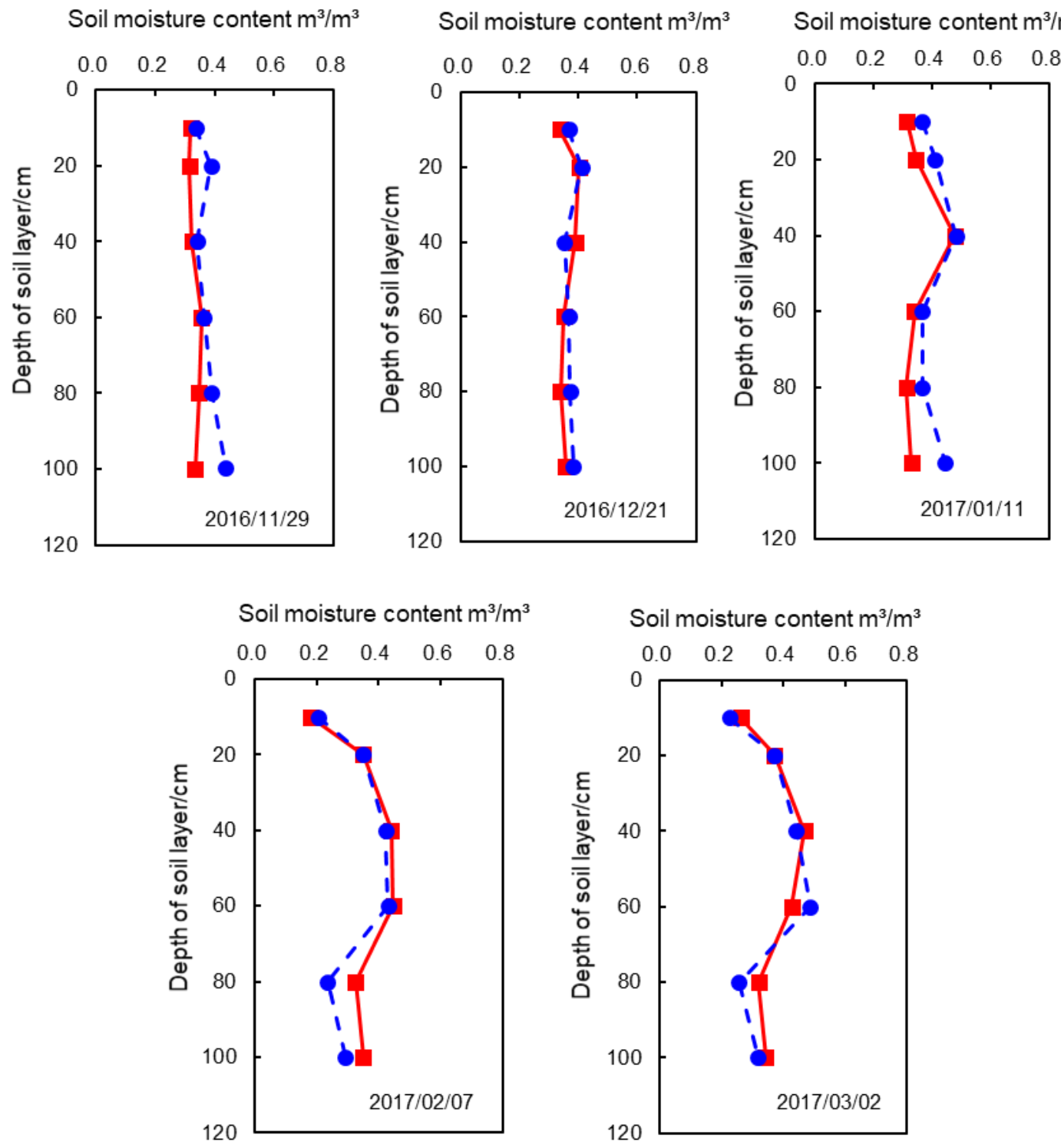

Figure 6. Simulated and measured values of soil moisture content in the freezing period. 


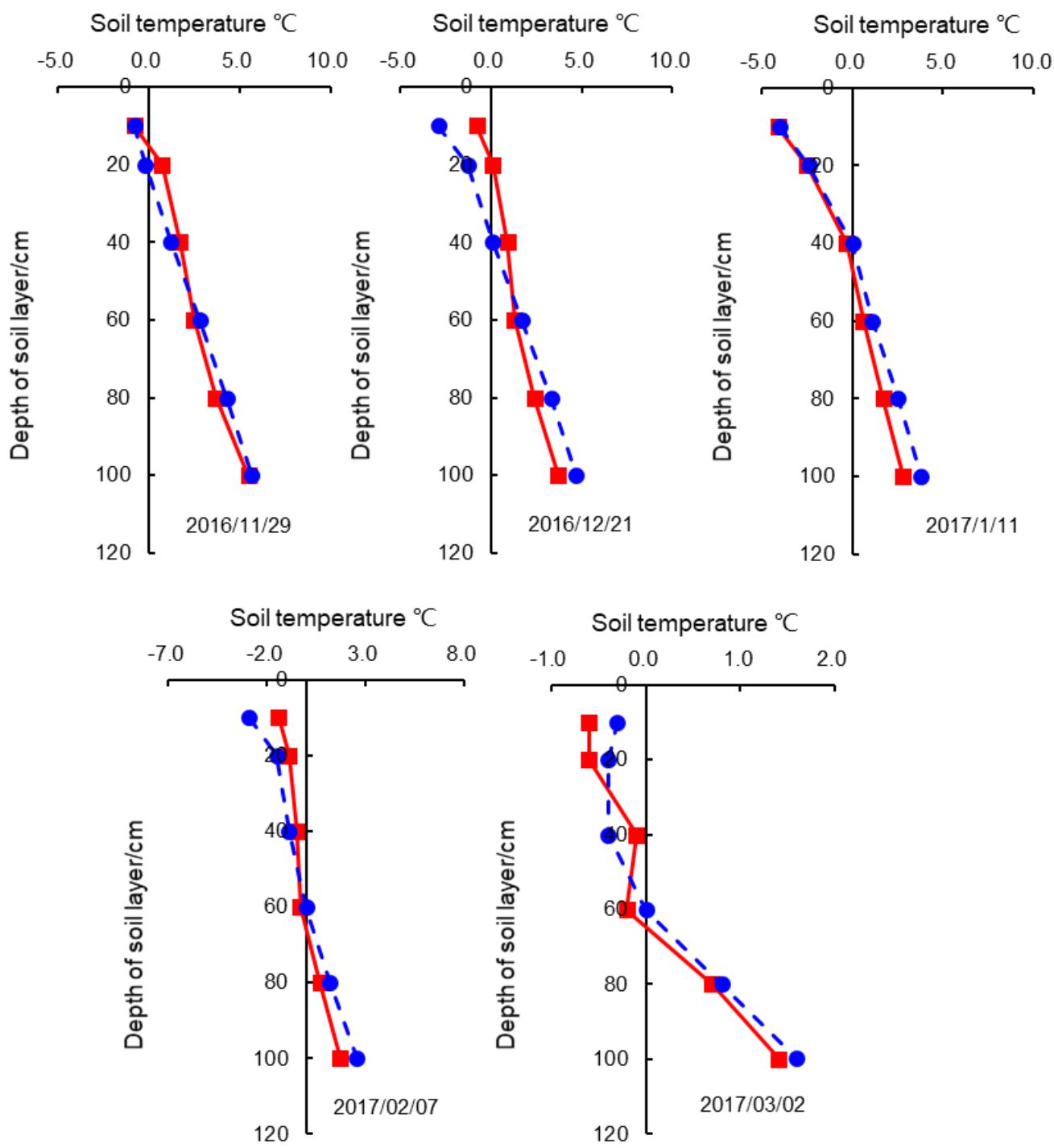

Figure 7. Simulated and measured values of soil temperature in the freezing period.

and the time sequence of reaching zero is respectively: 2016/ $11 / 21,2016 / 11 / 23,2016 / 12 / 17,2017 / 1 / 11$. The soil layer of 80 $\sim 160 \mathrm{~cm}$ does not reach zero degrees or below, which indicates that there is no freezing. Among them, the soil temperature of the $80 \mathrm{~cm}$ soil layer is close to zero, which is consistent with the fact that the deepest frozen depth measured in the actual soil sampling process reaches $75 \mathrm{~cm}$. At the same time, the SHAW model was used to simulate soil moisture content and temperature during the freezing period, and compared with the measured value, RMSE, $R^{2}$ and MRE were used to test. For soil moisture content, the mean values of MRE, RMSE and $R^{2}$ are $7.84 \%, 6.82 \%$, and 0.70 , respectively, which can better reflect the law of water movement in the freezing stage and the situation of soil water movement in the freezing stage. For soil temperature, the mean values of MRE, RMSE and $R^{2}$ are $25.80 \%$, $66.89 \%$, and 0.98 , respectively, which better reflect the change rule of temperature in the freezing stage. The SHAW model can simulate the change process of soil moisture and temperature in different soil layers in the freezing stage, and it also has a certain credibility.

Acknowledgements. This research was supported by the National Key Research and Development Plan (2016YFA0601502).

\section{References}

Batibeniz, F., Ashfaq, M., Diffenbaugh, N.S., Key, K., Evans, K.J., Turuncoglu, U.U. and Önol, B. (2020). Doubling of U.S. population exposure to climate extremes by 2050. Earth's Future, 8(4). https:// doi.org/10.1029/2019EF001421

Chen, Y.D., Zhang, Q., Xiao, M., Singh, V.P. and Zhang, S. (2016). Probabilistic forecasting of seasonal droughts in the Pearl River basin, China. Stochastic Environmental Research and Risk Assessment, 30(7). https://doi.org/10.1007/s00477-015-1174-6

Cheng, Q., Gao, L., Zhong, F., Zuo, X. and Ma, M. (2020). Spatiotemporal variations of drought in the Yunnan-Guizhou Plateau, southwest China, during 1960-2013 and their association with 
large-scale circulations and historical records. Ecological Indicators, 112. https://doi.org/10.1016/j.ecolind.2019.106041

Chuah, C.J., Ho, B.H. and Chow, W.T.L. (2018). Trans-boundary variations of urban drought vulnerability and its impact on water resource management in Singapore and Johor, Malaysia. Environmental Research Letters, 13(7). https://doi.org/10.1088/1748-9326/ aacad8

Dai, M., Huang, S., Huang, Q., Leng, G., Guo, Y., Wang, L., Fang, W., Li, P. and Zheng, X. (2020). Assessing agricultural drought risk and its dynamic evolution characteristics. Agricultural Water Manage- ment, 231. https://doi.org/10.1016/j.agwat.2020.106003

Deng, S., Chen, T., Yang, N., Qu, L., Li, M. and Chen, D. (2018). Spatial and temporal distribution of rainfall and drought characteristics across the Pearl River Basin. Science of the Total Environment, 619, 28-41. https://doi.org/10.1016/j.scitotenv.2017.10.339

Duan, R., Huang, G., Li, Y., Zhou, X., Ren, J. and Tian, C. (2020). Stepwise clustering future meteorological drought projection and multi-level factorial analysis under climate change: A case study of the Pearl River Basin, China. Environmental Research, 196. https:// doi.org/10.1016/j.envres.2020.110368

Kingston, D.G., Stagge, J.H., Tallaksen, L.M. and Hannah, D.M. (2015). European-scale drought: Understanding connections between atmospheric circulation and meteorological drought indices. Journal of Climate, 28(2). https://doi.org/10.1175/JCLI-D-14-000 01.1

Mishra, A.K. and Singh, V.P. (2010). A review of drought concepts. Journal of Hydrology, 391(1-2), 202-216. https://doi.org/10.1016/j. jhydrol.2010.07.012

Svoboda, M.D. and Fuchs, B.A. (2017). Drought and Water Crises: Integrating Science, Management, and Policy. World Meteorological Organization (WMO) and Global Water Partnership (GWP), Geneva. https:// doi.org/10.1201/b22009
Tisseuil, C., Vrac, M., Grenouillet, G., Wade, A.J., Gevrey, M., Oberdorff, T., Grodwohl, J.B. and Lek, S. (2012). Strengthening the link between climate, hydrological and species distribution modeling to assess the impacts of climate change on freshwater biodiversity. Science of the Total Environment, 424, 193-201. https://doi.org/10. 1016/j.scitotenv.2012.02.035

Ukkola, A.M., De Kauwe, M.G., Roderick, M.L., Abramowitz, G. and Pitman, A.J. (2020). Robust future changes in meteorological drought in CMIP6 projections despite uncertainty in precipitation. Geophysical Research Letters, 47(11). https://doi.org/10.1029/2020 GL087820

Wang, Z., Zhong, R., Lai, C., Zeng, Z., Lian, Y. and Bai, X. (2018). Climate change enhances the severity and variability of drought in the Pearl River Basin in South China in the 21st century. Agricultural and Forest Meteorology, 249, 149-162. https://doi.org/10.10 16/j.agrformet.2017.12.077

Weng, Q. (2007). A historical perspective of river basin management in the Pearl River Delta of China. Journal of Environmental Management, 85(4), 1048-1062. https://doi.org/10.1016/j.jenvman.200 6.11 .008

Xin, X., Yu, R., Zhou, T. and Wang, B. (2006). Drought in late spring of South China in recent decades. Journal of Climate, 19(13). https: //doi.org/10.1175/JCLI3794.1

Yang, P., Xiao, Z., Yang, J. and Liu, H. (2013). Characteristics of clustering extreme drought events in China during 1961-2010. Acta Meteorologica Sinica, 27(2), 186-198. https://doi.org/10.1007/s13351 -013-0204-X

Zhao, Y., Zou, X., Cao, L., Yao, Y. and Fu, G. (2018). Spatiotemporal variations of potential evapotranspiration and aridity index in relation to influencing factors over Southwest China during 1960-2013. Theoretical and Applied Climatology, 133(3), 711-726. https://doi. org/10.1007/s00704-017-2216-4 